\title{
Inadequacy of Neo-classical Theory and Its Reflection on the Market Economy
}

\author{
Selda Atik ${ }^{1}$ \\ ${ }^{I}$ (Depatment of Economics/ Başkent University, Turkey)
}

\begin{abstract}
The hypothesis and proposed policies of Neo-classical theory as the dominant ideology of economics in today, are becoming increasingly ineffective in solving current problems and even sometimes cause problems to be intensified. The most important reason for this is the failure of creating a healthy structure for the hypothesis of Neo-classical theory in order to implement it in the reality of today's market economies. The fact confirms the inadequacy of the theory is that even the signals of the recent global economic crisis were not noticed by the economists and the necessary precautions were not taken. The Neo-classical theory was dominating the system since it had emerged mainly focused on pure mathematical models in order to get economics closer to the natural sciences and therefore gradually detached from the social reality and created a fictional economical world. In the study examines the inadequacy of the Neo-classical theory, its reflection on market economics and concludes that a new perspective is needed to produce realistic solutions.
\end{abstract}

Keywords" Ceteris paribus, laissez faire, Neo-classical theory, market economy, Pareto optimal

\section{Introduction}

The hypothesis and proposed policies of Neo-classical theory as the dominant ideology of economics in today are becoming increasingly ineffective in solving current problems and even sometimes cause problems to be intensified.The most important reason for this is the failure of creating a healthy structure for the hypothesis of Neo-classical theory in order to implement it in the reality of today's market economies. However, in recent years, Neo-classical theory of economics has been questioned increasingly and the various circles has begun to voice that it should be reviewed in the light of real world events. For example, the signals of the global economic crisis, which began in the middle of the year 2008 in USA, were not detected by many economists and the sacred rule (market economy should never to be interfered) was defended up to the end. The economists who issued warnings against it were accused of being pessimists or not thinking scientifically. However, the clear truth is that although the Neo-classical theory of economics as the dominant perspective has no longer have a solid grasp of real events, cannot find solutions to problems or even detect of the signals of the problems. In this study, the basic hypothesis of Neo-classical economics were examined in the context of reality of market economy and the problems and discrepancies of the practice were presented with a critical perspective.

\section{Neo-Classical Economics As The Dominant Ideology And Controversial Basic Hypothesis}

Neo-classical theory maintains its dominant position in economics for more than a century. The classic economists lived in the beginning of industrial capitalism but the industrialization and urbanization gained speed since then and brought many social problems during the ongoing process. The laissez-faire principle, which is the foundation stone of classical theory, has damaged by the increasing intervention of the states as a result of emerging social problems, and at the end of the 19th century, the serious criticisms of the capitalism made it impossible to stay neutral about the social order. (Guerrien, 1999: 9)

It is possible to say that Leon Walras ( French economist Leon Walras developed the idea of marginal utility and is thus considered one of the founders of the "marginal revolution") draws the general outline of modern Neo-classical theory. Alfred Marshall, a contemporary of Walras, used a partial equilibrium analysis to maintain Adam Smith tradition and focused on partial equilibrium in single markets. Nevertheless, the absence of time intervals of the analysis prevented to reach general equilibrium model. In order to avoid this difficulty, Walras preferred to use a static model which opened the way to mathematical analysis (Thomson, 1997: 28). It is possible to build a static model based on mathematical structure just like physics. In this framework, the static model played an important role in advancing economics to become science similar to natural sciences. Concepts and the intelligent methods produced by Pareto, Hicks, Samuelson and similar made it possible to achieve radiant concepts such as perfect competition and pareto optimum (Boland, 2002: 98).

Neo-classical theory, which can also be defined as a revision of classical school, was influenced by the development of Marxism and attempted to re-describe the theory of value (Wallerstein, 1996: 93). Although the macroeconomic approach of the classics were preserved, microeconomic perspectives were highlighted in order to examine the behaviours of small decision units such as producers and consumers. While Neo-classics 
attempted to explain the value from a new angle, the objective real cost has left its place to subjective real cost as from the 1870s. The new theory has been based on psychological factor, the benefit was underlined, and also the labour-time has left its place to subjective labour as the determinant of the value. In this framework, the Neo-classical economics combine the schools of economics that is united in the understanding of marginal value and distribution. (Mousavi and Garrison, 2003: 131). If we need to summarize the most criticized assumptions of Neo-classical theory under general headings, we could list four basic hypotheses. These are; homo economicus (economic human), perfect competition conditions and profit maximization and ceteris paribus (other conditions are constant). (Brenner, 1999: 89)

\subsection{Homo Economicus}

The hypothesis of Homo economicus can be regarded as a common denominator of Classical and Neo-classical theories. This concept assume that if the individuals act according to their own interests, they also behave in a way to increase the prosperity of the society in the long term. The main problem here is if it can explain the behaviours of so-called average consumer (producer) in general. Homo economicus is a person who has full knowledge of the products, markets and other economic issues, who can make an absolute evaluation of the options and who prefers the most to the less, and whose preferences do not conflict with each other. While homo economics consumers maximise their benefits, the producers can maximise their profits (Çeçen, 2004: 221). Daniel Kahneman, who received the Nobel Prize for economy in 2002, demonstrated that the individuals systematically can behave in a way that is incompatible with the rational model in the situations of uncertainty and risk. Kahneman's welfare theory was developed in this direction and makes the validity of the hypothesis questionable, which is the most powerful assumption of Neo-classical theory (Kahneman and Tversky, 1979: 263)

\subsection{Perfect Competition}

Another hypothesis of Neo-Classical theory is the conditions of perfect competition. Although it is possible to list them as below, it is nearly practically impossible to realize the conditions perfect competition in real economic life. (Finlayson et al., 2005: 530)

- The mobility condition is based on full freedom of the buyer, seller and production factors. The condition cannot always be fulfilled due to the number of factors in the real economic life and cause the total number of the companies to be fewer than $\mathrm{n}$.

- The atomicity condition assumes that the society is formed by the individual human beings and accept them as a basic unit, just as the atom for physicists and genes for the biologists. Although the society is formed by the individuals, it is also consist of the classes, political groups, trade unions, religious communities and ethnic groups.

Furthermore, the individuals are not made of one-type structure (rational individual) as neoclassical The condition of explicity assumes that the buyers and sellers know all the prices on the market and they are aware of all inflows and outflows. However, it is one of the most difficult conditions to implement in practice, especially in goods markets, because of the various obstacles of time and location. (Weintraub, 1999: 140)

- The condition of homogeneity assumes that the buyer, the seller and the goods are the same. However, this condition cannot be ensured in practice due to the psychological and locational reasons, as well as the fact that firms implement advertising and goods differentiation with an aim to .increase their market share

- The condition of explicity assumes that the buyers and sellers know all the prices on the market and they are aware of all inflows and outflows. However, it is one of the most difficult conditions to implement in practice, especially in goods markets, because of the various obstacles of time and location. (Weintraub, 1999: 140)

The condition of explicity assumes that the buyers and sellers know all the prices on the market and they are aware of all inflows and outflows. However, it is one of the most difficult conditions to implement in practice, especially in goods markets, because of the various obstacles of time and location. (Weintraub, 1999: 140)

\subsection{Profit Maximization}

Another controversial hypothesis is the profit maximization. Neo-classical economics assumes that the ultimate goal of every firm is the maximisation of the profit, whatever the market conditions are, and they will increase the amount of their productions until the marginal costs equal to the marginal revenue and also presume that the sales prices will be determined according to this production amount. However, it is not possible for companies to know the demand and cost in real life or have full knowledge of the elasticity of demand for the goods they produce. It is not possible to make marginal calculations or ensure divisibility in many production fields (Simon, 1979: 493) 
Inadequacy of Neo-classical Theory and Its Reflection on the Market Economy

\subsection{Ceteris Paribus}

Finally, ceteris paribus hypothesis assumes that only one of the variables changes but all the other variables remain constant during the examination of an economic phenomenon. This assumption allow economists to create theories and make analyses but also leads to detachment from the reality by simplifying the logic (Solow, 1985: 328)

\section{Implementation Problems of Neo-classical Theory in The Market Economy 3.1. The Problem of Failure to Detect the Signals}

The problems related to functioning of market economy and the Neo-classical theory are not only wrong but also dangerous and caused the emerge of the recent global crisis. The theory of Neo-classical economics directly affected the crisis of today, due to the belief in market economy and natural stability (Keen, 2009: 2) Neo-classical theory has contributed to the increase in market instability by preventing intervention to the system, in line with its false laissez-faire belief. At this point, the instability in the financial markets, which is the main starting point of the crisis, threatens the existence of dominant economic view. Even the most prominent signals of the crisis, bubbles of the financial markets, growing private debts have not been noticed by economists. Moreover, even the approach of the perfect storm, which is often mentioned in the literature of economics and used to mean global economic crises, did not cast any doubt in the minds of neoclassical economists who believe in the market cycle (Galbraith, 2009: 62). Although the system exclude control of financial institutions and market, whenever a financial crisis occurs, it became necessary to transfer public funds to the markets in order to prevent the damage caused by speculations. In the pre-crisis period, positive developments in macroeconomic balances, such as positive economic growth, low inflation and decline in economic fluctuations had strengthened the concept of market balance, which is the basic foundation of Neoclassical economists' system (Costanza, 2009: 20). However, the governments and the business communities ignore the warnings that economic growth was the result of market price increase at the speculative markets, not at the physical markets. As a matter of fact, the people, who indicate the signals and talks negatively about the system, were criticized harshly for arguing that the market is unstable and accused of not thinking academically by the academic circles (Keen, 2009: 8). The reason for the accusations was the confidence in the intensive mathematical models used as a base for the estimates in the financial markets and the trust in accuracy of academic studies which are believed to be more scientific.

\subsection{Behavioural Differences between Rational Individual and Homo Economicus}

In addition to preventing intervention to the system, the other the basic assumption of Neo-classical theory that prepares the acceleration process of the crises is the phenomenon of homo-economicus. This machine human structure, which thinks rational, always pursue benefit maximization and prefer the most to the less, is one of the most reliable and undoubted structures of the system. Unfortunately, the rational human vision and the structure of financial markets did not provide the anticipated combination and the individuals took more debts above their capacities and put the benefit maximisation aside during the course of the global crisis (Turton, 2009: 83) Trading on the financial markets is based on the movements and intentions of others, not on the long-term supply-demand relationship. The people, who buy financial instruments at high price and sell at less price, are always considered as irrational and believed that the rational person should always buy at low price and sell at a higher price. According to Kahneman, who received the 2002 Nobel Prize in economics, (Radikal, 13/10/2002); In the case of risk or uncertainty, human behaviours can be differentiated from the rational human behaviours, resulting with non-optimal outcomes. However, the hypothetical human behaviours are assumed to be systematic and predictable. For example; A trader may want to sell his equity share, which was purchased at 50 dollars, when the stock market has risen to 70 dollars. Conversely, investor $B$, who bought the same equity share at 90 dollars would be reluctant to sell his shares, although he knew they were overvalued at 70 dollars. In such a case it is difficult to argue that the attitude of the second investor is rational. Financial market actors who think that a rational person would not like high risk and uncertainty and therefore they offer a loan package instead of offering singular high-risk subprime loans (these are the loans which are given to the people with unclear credit history or who had difficulty in paying previous loans or those with risk of not paying) in order to decrease risks and make it safer for the market. From an external perspective, the invisibility of the risks can cause these financial assets to be seen much safer and to be presented to the people easily. The question at this point is if the individuals were purchasing high-risk financial assets because if they are rational, or because if the other individuals purchase them. As a matter of fact, when the risk of subprime loans credits start to increase in the market, the false confidence disappear and the market start to dissolve quickly with the domino effect (Katsuhito, Tokyo Foundation: 12/08/2008)

\subsection{Excessive Use of Mathematics and Becoming Distant from the Social Reality}

Perhaps the most criticized subject of Neo-classical theory is the excessive use of mathematics. The indispensability of mathematics as a scientific method is indisputable. However, the use of mathematics in social sciences cannot be comprehensive and determinative as the natural sciences such as physics. Because the 
behaviours of the individuals are not based on absolute reasoning, the social relations are complicated and unpredictable that it cannot be reflected with mathematical language. Even if the relationships were defined mathematically, they often presented in very extensive framework that exceeds the individual's judgment capacity. The advanced and intensive use of mathematics, which is sometimes even difficult for the mathematicians to understand, show the necessity of serious questioning of the methods of studying social dynamics of economics. (Acar, 2009: 19) Critics argue that science of economics is not a science of nature. Economics is a social science and it is very difficult or even impossible to make definite judgments. Policies that are valid for a certain period of time may lose their validity as society's structure and habits change. For this reason, the mathematical application of the economics does not mean that it consist of complete set of unchangeable laws.

\subsection{Neo-classical Paradigms Causing Financial Crises}

The global economy, has been directed to speculations and Wall-Street with short-term and pragmatic economic policies, instead of long-term and lasting policies due to the Neo-classical paradigms that are considered to be indispensable. This transition not only brought about economic collapse, it has also largely prevented long-term initiatives such as economic growth, infrastructure renewal, climate change mitigation, adequate capital flows, and alternative energy sources that required for a sustainable economic equilibrium. (Krugman 2008:19)

It is possible that the neoclassical paradigms leading to the global economic crisis are listed as follows

- Markets are often stable in balance, or close to the balance.

- Market actors (consumers and producers) behave rationally in order to maximize utility.

- Market actors are assumed to have complete and perfect knowledge of the market.

- $\quad$ Prices are determined to maximize the interests of everyone involved in the trade.

- The fluctuations in prices are small, random, and disconnected.

- There is excellent liquidity flow in the markets, where all prices are well defined and all markets are clean.

- There is no difference between the simple models where the markets for a few people are involved and those made of millions. Simple models are enough to illuminate the principles governing the markets.

Nevertheless, the recent global economic crisis shows that there are serious weaknesses in the Neoclassical paradigms; (Sean, 2009: 36)

- The prices of financial instruments, commodity prices and fluctuations in currencies are not random and unconnected. Perhaps a more realistic paradigm is needed to explain the functioning of real markets.

- The competitive general equilibrium model is more ideal than the real life operation of the markets.

- Market actors do not have a clear preference as the general equilibrium theory assumes. Preferences and conditions change. For this reason, risk assessments that do not anticipate innovations are problematic.

- The simple fictional models, which consist of two individuals and two goods, can not account for real markets consisting of millions of individuals and thousands of goods.

- Market actors can not always have perfect and complete knowledge. In fact, knowledge and beliefs about market conditions can be wrong or untrustworthy. Or it is possible that different individuals have different knowledge and beliefs.

- It is possible that serious misconceptions arise in estimates of market sizes. For example; Financial instruments and derivatives are only a small part of the market, the risk is low. However, it is becoming increasingly difficult for the market to make risk (loss) forecasts when the use of such instruments is increasingly used.

- Economics is a physical system involving the flow of goods, information and energy. An economic model conceived as a physical system in this framework may be useful for science.

- However, the physical equilibrium model is valid only for closed systems, an economic system consisting of open markets can not be adapted to the equilibrium model.

\section{Conclusion}

Neo-classical theory has taken dominant position in the economics since it emerged but it also caused the science of economics to became increasingly ineffective in solving today's economic problems. The policies suggested by the Neo-classical economy could not bring solutions to problems and even sometimes deepen the problems by getting distant from reality. The study of economics within the framework of natural sciences has brought intensive use of mathematics and cause economics scholars to create fictional models which are distant from the operation of real markets. From this point on, the economic theories are not 
constructed in the direction of the present reality but in line with desired targets of the advocators of the system. The assumptions such as homo economicus, laissez-faire and utopic competitive markets and the stability of markets have caused the methodology of economics to detached from the social reality and drag it to a completely different direction. The criticisms of the dominant economic ideology have been verified in a sense, considering the fact that even the signals of the recent global economic crisis were not noticed by the economists. Macroeconomic arguments, such as positive growth rates, low inflation and gradual decrease of the fluctuations, were used as strong evidences to support that there were no economic problems until the beginning of the crisis. On the other hand, the circumstances of gradually swollen financial markets, increasing demand for risky credits, increasing amount of private loans to finance these credits were ignored. The economists turned a deaf ear to the dangerous signals of the economy and also the people who expressed their concerns about it were strongly criticized. Neo-classical theory, which has dominated the system since it had emerged, focused on pure mathematical models in order to get closer to natural sciences but it caused a gradual detachment from the social reality and created a world of fictional economics and therefore a new perspective is needed to produce realistic solutions to problems.

\section{References}

[1] Acar, G. T. (2008), İktisadı Değiștirmek: Neoklasik İktisada Eleştirel Bir Yaklaşım( Changing Economics: A Critical Approach to Neoclassical Economics), 1. ed. İletişim, İstanbul.

[2] Boland, L. A. (1997), Critical Economic Methodology: A Personal Odyssey,Routledge, London

[3] Boland, L.A.(2002), “Applying Economic Methodology: Recognizing Knowledge in Economic Models”, International Journal of Philosophy and Methodology of Economics, vol.1, p. 82-95

[4] Brenner, R. (1999). "Dünya kapitalizminin Yaklaşan Krizi: Neo liberalizmden Buhrana mı (The Upcoming Crisis of World Capitalism: To Depression From Neo-liberalism)", trans. Pınar Bedirhanoğlu, Birikim 119, p.88-95

[5] Costanza, R. (2009), "Toward a New Sustainable Economy”, Real-World Economics Review, vol.49, part II, p.20-32

[6] Ceçen, A. (2004), "Rasyonel Eylem, Aksiyomatik Bilgi ve Homo Economicus (Rational Action, Axiomatic Information and Homo Economicus)" ", İktisat Üzerine Yazılar I( Writings on Economics), İletişim, İstanbul.

[7] Finlayson,C. Alan, N, Thomas, A. (2005) "The Invisible Hand Neoclassical Economics and The Ordering of Society" Critical Sociology, vol.31, no.4, pp.515-536

[8] Galbraith, J. K. (2009), "Statement to The US House of Representative" Real-World Economics Review, vol.49, part IV, p.62-80

[9] Guerrien, B. (1999), Neo-Claasical Economics, (translate.. Ertuğrul Tokdemir), 2nd ed. İletişim publications, İstanbul.

[10] Kahneman, D. \& Tversky, A.(1979) "Prospect Theory: An Analysis of Decision Under Risk" Econometrica, vol.47, no.2, pp.263291.

[11] Katsuhito,I.(2008)“Global Financial Crisis Shows Inherent Instability of Capitalism Capitalism” TheTokyoFoundation, 12.08.2008, date of access;19.04.2017 http://www.tokyofoundation.org/en/articles/2008/global-finacial-crisis-shows-inhere..

[12] Keen, S. (2001) Debunking Economics:The Naked Emperor of The Social Sciences, Pluto Pres, Zed Books, Sydney\&London

[13] Kuhn, T. S. (1970) The Structure of Scientific Revolutions, Chicago IL: The Universty of Chicago Press

[14] Krugman, P. (2008) The Return of Depression Economics and the Crisis of 2008, W.W. Norton, Seeking Alpha, hardcover, pp.224

[15] Mousavi, S. \& Garrison, J. (2003) "Toward a Transactional Theory of Decision Making: Creative Rationality as Functional Coordination in Context" Journal of Economic Methodology, vol.10, p. 131-156

[16] Sean, M (2009) “A Non-Formal Look at The Non-Formal Economy” Real World Economics Review, vol.49.partII, pp. 36-42

[17] Simon, H. A.(1979) "Rational Decision making in Business Organizations" The American Economic Review, vol. 69, pp.493-513

[18] Solow, R. M. (1985) "Economic History and Economics”, The American Economic Review, vol.75, no.2,pp. 328-331

[19] Thomson, G.(1973) Capitalism and After: The Rise and Fall of Commodity Price, China policy study group, London

[20] Turton, D. (2009) "The Real Dirth on Happiness Economics: A Reply to The Unhappy Thing About Happiness Economies” RealWorld Economics Review, vol.49, Part II, pp.83-94

[21] Wallerstein, I. (1996) Historical capitalism with Capitalist Civilization. Verso, London, NewYork

[22] Weintraub, R.E. (1999) "How Should we Write The History of Twentieth Century Economics?" Oxford Review of Economic Policy, vol.15, pp.139-152 